\title{
Decameter mid-latitude sporadic-E irregularities in relation with gravity waves
}

\author{
A. Bourdillon ${ }^{1}$, E. Lefur ${ }^{1}$, C. Haldoupis ${ }^{2}$, Y. Le Roux ${ }^{3}$, J. Ménard ${ }^{3}$, J. Delloue ${ }^{4}$ \\ ${ }^{1}$ Laboratoire Structures Rayonnautes, UPRES-4 CNRS 6095, Université de Rennes 1, Rennes, France \\ ${ }^{2}$ University of Crete, Iraklion, Crete, Greece \\ ${ }^{3}$ France Télécom, CNET/LAB/SAR/TSI, Lannion, France \\ ${ }^{4}$ Laboratoire de Physique de l'Exosphère, Université Pierre et Marie Curie, Paris, France
}

Received: 21 August 1996 / Revised: 20 February 1997 / Accepted: 24 February 1997

\begin{abstract}
HF radar observations of mid-latitude sporadic-E irregularities carried out with the Valensole radar in South France are compared with simultaneous ionosonde measurements underneath the irregularity zones. In a previous study of Valensole radar data, it has been shown that HF backscatter from the night-time mid-latitude $\mathrm{E}$ region is usually associated with largescale wave-like modulations. To obtain more information on the geophysical conditions prevailing during backscatter events, a new experiment was performed which also included a vertical ionosonde beneath the scattering region. The data to be presented here are from two periods when radar scattering appeared simultaneously with large variations in the virtual height and the Doppler velocity of F-layer reflected echoes measured with the vertical ionosonde, indicating very clearly the passage of atmospheric gravity waves (AGWs). The effect of the atmospheric waves on the sporadic-E layer is not always as marked as it is in the F region. In the first event, the passage of the AGWs is accompanied by an upward followed by a downward movement of the Es-layer. The apparent descending movement of the Es-layer from 135 to $110 \mathrm{~km}$ in less than $10 \mathrm{~min}$ corresponded to a positive (downward) Doppler velocity of $35 \mathrm{~m} / \mathrm{s}$ measured by the vertical ionosonde, and was accompanied by a range variation in the radar scattering region with a negative rate of about $90-110 \mathrm{~m} / \mathrm{s}$. In the second event, the Es-layer is not as strongly disturbed as in the previous one, but, nevertheless, the range variations of the scattering region can still be associated with height fluctuations of the Es-layer.
\end{abstract}

\section{Introduction}

Mid-latitude sporadic-E scattering is regularly observed by $\mathrm{HF}$ and VHF radars during summer at night (Goodwin, 1965; Ecklund et al., 1981; Tanaka and
Venkateswaran, 1982a, b; Keys and Andrews, 1984; Riggin et al., 1986; Fukao et al., 1991; Yamamoto et al., 1991, 1992, 1994; Haldoupis and Schlegel, 1993; Bourdillon et al., 1995); nevertheless, this phenomenon is not yet fully understood.

The gradient drift instability is usually believed to be at the origin of the observed field-aligned irregularities. In a simple model, with a horizontally stratified sporadic-E layer, the gradient drift mode can produce waves with $\mathrm{k}$ vector lying mainly in the $\mathrm{E}-\mathrm{W}$ direction (primary waves) so that a northwards-looking radar might only observe secondary waves generated by the gradient resulting from the primary waves, as explained by Sudan et al. (1973). The real situation can be more complicated in irregular layers, for instance in partially reflecting layers and in spread Es (From and Whitehead, 1986) inside which one can expect that non-vertical density gradients also exist. VHF and HF radar observations revealed that the scattering layer is very often affected by spatial modulation of the backscattered power and also of the Doppler shift and width (Riggin et al., 1986; Fukao et al., 1991; Yamamoto et al., 1991, 1992, 1994; Bourdillon et al., 1995). Riggin et al. (1986) attributed their observed large-scale structures and the associated high velocities, sometimes exceeding $250 \mathrm{~m} / \mathrm{s}$, to kilometer-scale plasma waves generated by the gradient drift instability. This interpretation was disputed by Woodman et al. (1991) because the width of an Es-layer is too small for the gradient drift mode to be operating at the kilometer scale. Woodman et al. (1991) suggested that atmospheric gravity waves (AGWs) could modulate the Es-layer in altitude. To be efficient, this mechanism needs a resonant interaction between the AGW and the plasma, which can be obtained for southward propagating waves and for specific values of wave period. Recently, Tsunoda et al. (1994) discovered that inside an Es-layer modulated in altitude, polarization electric fields could develop because the Pedersen ion velocity is altitude dependent. In their model, the polarization field strongly reinforces the background field when the layer is at low altitude $(\sim 100 \mathrm{~km})$, and 
slightly decreases the field when the layer is at high altitude $(\sim 120 \mathrm{~km})$. Tsunoda et al. (1994) suggested that this polarization process could explain the large variations in the Doppler velocity measured in the scattering region.

In a previous paper (Bourdillon et al., 1995), the general characteristics of multi-beam observations of mid-latitude sporadic-E scattering, carried out with the Valensole HF radar in South France, were presented. In particular, it was shown that the scattering region is often modulated by large-scale waves as has been observed with the MU radar at a higher frequency of 46.5 MHz (Yamamoto et al., 1991, 1992, 1994; Woodman et al., 1991; Tsunoda et al., 1994). The aim of this paper is to present observations of sporadic-E irregularities detected with the Valensole HF radar, while a digital vertical ionosonde, operating beneath the region of aspect sensitive scattering of the radar, monitored the height and the critical frequencies of the sporadic-E and of the F-layers and measured the Doppler shifts of the echoes.

The experimental configuration for the HF radar and the vertical ionosonde is briefly described in Sect. 2 of the paper, the data collected by the two instruments are presented in Sects. 3 and 4, and a discussion is given in Sect. 5 with concluding remarks.

\section{The Experiment}

\subsection{The HF Valensole radar}

The radar of the University Pierre et Marie Curie, in Valensole, has already been described in Bourdillon et al. (1995) and in Six et al. (1996), so here we provide only a brief description of the experiment.

The system is a monostatic coherent radar transmitting $100-\mathrm{kW}$ peak power pulses with a maximum duty cycle of $2 \%$. The transmitting antenna array is formed with four broadband vertical elements, and provides a wide azimuthal coverage of $70^{\circ}$ at $9 \mathrm{MHz}$. The receiving array, $550 \mathrm{~m}$ long, comprises 48 pairs of vertical elements organized in 12 sub-arrays and 11 receivers. The receiving beam is steered by delay lines in steps of $12^{\circ}$. A full radar scan is performed in $80 \mathrm{~s}$ and comprises seven sectors of $12^{\circ}$ width. Inside each sector, six beams separated by $2^{\circ}$ are formed by the computer.

The transmit waveform was a Gaussian pulse $145 \mu \mathrm{s}$ in width, providing a $22-\mathrm{km}$ range resolution. The received signal was sampled every $18 \mathrm{~km}$ in 15 range gates extending from 100 to $370 \mathrm{~km}$ from the radar. The unambiguous range and Doppler velocity were $2250 \mathrm{~km}$ and $\pm 555 \mathrm{~m} / \mathrm{s}$ at $9 \mathrm{MHz}$, respectively. The 3 -dB beamwidth transverse resolution at $9 \mathrm{MHz}$ varied from $7 \mathrm{~km}$ at $100-\mathrm{km}$ range to $26 \mathrm{~km}$ at $370-\mathrm{km}$ range. For each resolution cell, 128-point Doppler spectra were computed and four spectra, taken consecutively in time (dwell time: $7.68 \mathrm{~s}$ ), were incoherently averaged before recording on disk. The Doppler velocity resolution was $8.7 \mathrm{~m} / \mathrm{s}$.

\subsection{The digital vertical sounder}

The vertical digital sounder SCIPION, an acronym for "Système Compact d'Investigation de la Propagation Ionosphérique", has been developed by France Télécom-CNET (Centre National d'Etudes des Télécommunications) in Lannion.

The SCIPION system, which can be used for vertical or oblique sounding of the ionosphere, is a digital sounder making intensive use of signal processing to obtain good-quality results with a relatively low transmitted power (10 W typical value) and an unambiguous $50-\mathrm{dB}$ dynamic range after processing.

The sounder schedule was the following: every $4 \frac{1}{2}$ min the sounder performed a frequency sweep from 2 to $10.34 \mathrm{MHz}$ with $60-\mathrm{kHz}$ steps and then transmitted four fixed frequencies for Doppler analysis purposes. The virtual height resolution was $3 \mathrm{~km}$ and, in the fixed frequency mode, the Doppler was analysed in the band from -1.22 to $+1.22 \mathrm{~Hz}$ with a $9.5-\mathrm{mHz}$ resolution.

For the experiment the sounder was installed on a site near Grenoble, $150 \mathrm{~km}$ north of Valensole, i.e. just under the region of aspect sensitive scattering for the radar in azimuth $10^{\circ} \mathrm{W}$ (Fig. 1).

\section{Experimental data 26 July 1994}

\subsection{Radar data}

Figure 2 shows four scans at $9 \mathrm{MHz}$ that were obtained on 26 July 1994 between 2112 UT and 2120 UT $(\mathrm{LT}=\mathrm{UT}+0024)$. Only the azimuths from $22^{\circ} \mathrm{W}$ to $12^{\circ} \mathrm{E}$ and ranges between 154 and $262 \mathrm{~km}$ are shown.

Valensole HF radar $(43.8 \mathrm{~N} ; 6.0 \mathrm{E})$ : field of view Magnetic aspect angle geometry at Es Altitudes (IGRF-93) Altitude range 90-120 km Magnetic aspect angle range (dg): 89.7-90.3



Fig. 1. The experiment performed with the radar of Valensole looking northwards. The ionospheric sounder SCIPION was located $150 \mathrm{~km}$ north of the radar ( 190-km radar range at $110-\mathrm{km}$ altitude) in azimuth $10^{\circ} \mathrm{W}$. The receiving antenna pattern includes 42 elementary beams each having a $2^{\circ}$ beamwidth. Also shown are the 15 radar ranges, from 100 to $352 \mathrm{~km}$, and the best magnetic aspect angle region (dotted area) for aspect sensitive backscatter at E-region altitudes between 90 and $120 \mathrm{~km}$ 

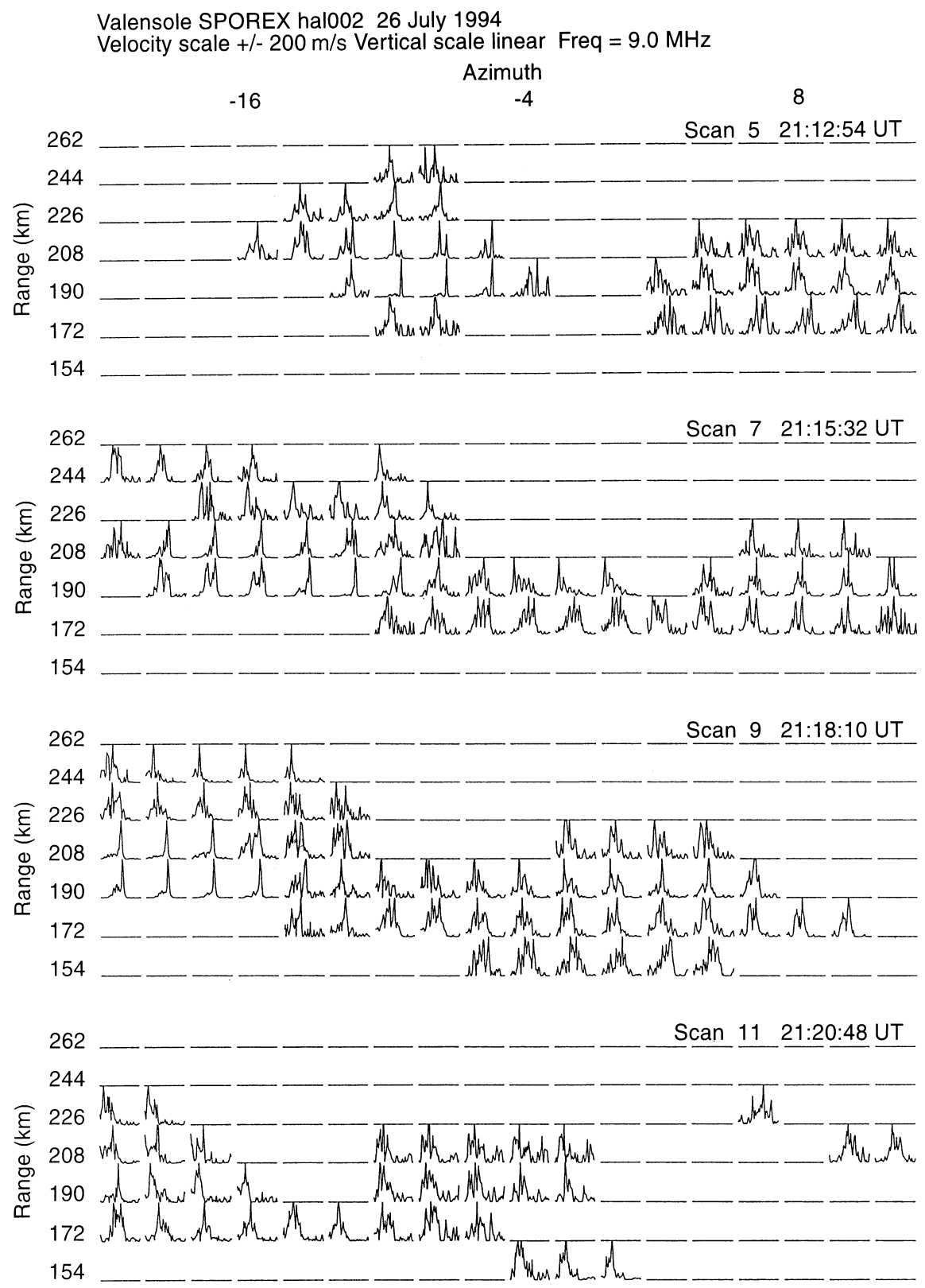

Fig. 2. Four radar azimuthal scans from $22^{\circ} \mathrm{W}$ to $12^{\circ} \mathrm{E}$ showing E-region magnetic aspect sensitive echoes at $9 \mathrm{MHz}$. The scans were performed at 2.5 -min intervals. The Doppler spectrum for any cell is linear with the Doppler velocity ranging from -200 to $200 \mathrm{~m} / \mathrm{s}$. Note the sharp spectra, localized to 3 or 4 adjacent beams, which are observed to move westwards at a velocity of $130 \mathrm{~m} / \mathrm{s}$
Inside each cell the self-normalized linear Doppler spectra are plotted using a velocity scale limited to $\pm 200 \mathrm{~m} / \mathrm{s}$. The spectra with the $\mathrm{S} / \mathrm{N}$ ratio below a threshold of $2 \mathrm{~dB}$ were rejected. It should be noted that scattering by field-aligned irregularities is aspect sensitive and thus the scattering region is mainly determined by the orientation of the magnetic field with respect to the radar beam. For instance, scan 9 shows a typical Ushaped scatter distribution with range and azimuth centred on the magnetic-North direction which simply reflects the aspect sensitivity of the scattering process. For more detail on the aspect sensitivity region of the Valensole radar see Bourdillon et al. (1995). The refraction and large-scale wave effects can also be important. In Fig. 2 the scattering region is not spatially homogeneous, but it is modulated by a large-scale wavelike pattern affecting the Doppler velocity on spatial scales of a few tens of kilometers. Also, the spectral width varies inside the scattering region, and two kinds of spectra can be identified. Scan 5 (Fig. 2) shows very narrow spectra in the centre of the western part of the scattering region, while the eastern part shows broad spectra only. Scans 7 and 9 show more homogeneous backscatter within the scanned region. The zone of narrow spectra has gradually shifted westwards and eventually moved out of the radar field of view (scan 11). The azimuthal displacement of the narrow spectra region was $42 \mathrm{~km}$ between scan 5 and scan 9 which corresponds to a westward velocity of nearly $130 \mathrm{~m} / \mathrm{s}$.

Figures 3 and 4 show the Doppler spectra (range gates between 118 and $280 \mathrm{~km}$ ) for azimuth of $10^{\circ} \mathrm{W}$ (i.e. in the azimuth of the ionosonde; see Fig. 1) in the timeperiods of 2106-2208 and 2211-2313 UT, respectively. In these plots the vertical scale is in $\mathrm{dB}$ and each spectrum is normalized to the maximum power for each time-period separately. 


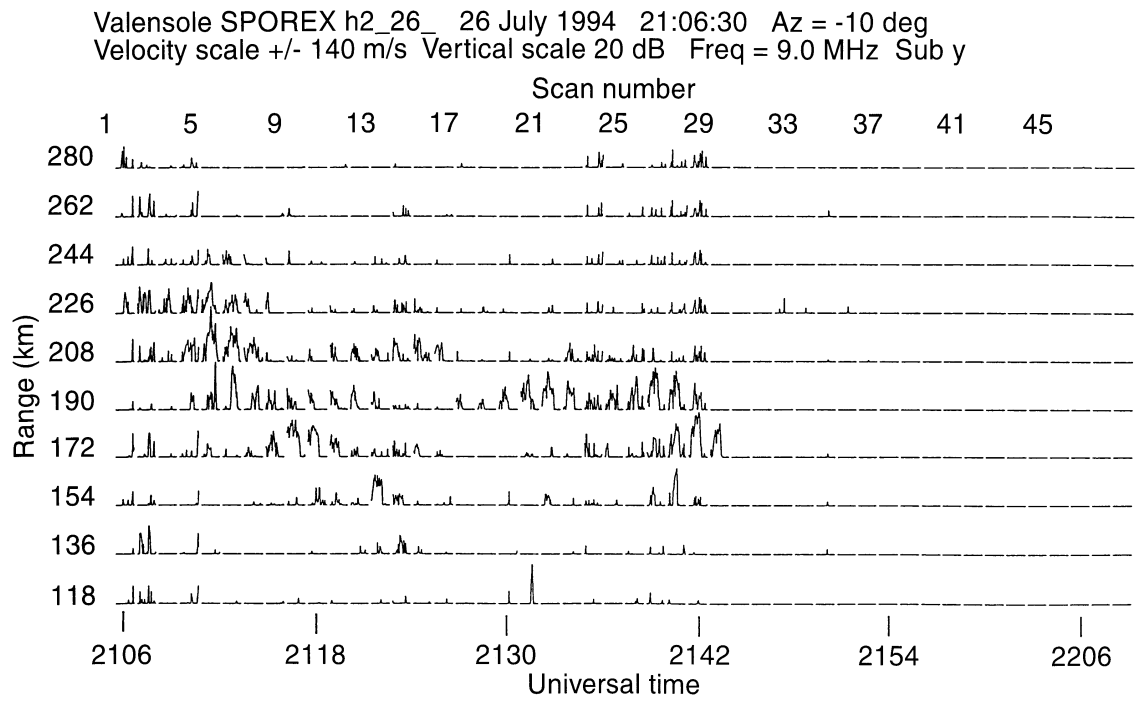

Fig. 3. Time evolution of E-region aspect sensitive echoes at $9 \mathrm{MHz}$ in azimuth $10^{\circ} \mathrm{W}$, in the time-period 2106-2209 UT. The Doppler spectrum at any cell is logarithmic on a $20-\mathrm{dB}$ scale with the Doppler velocity ranging from -140 to $140 \mathrm{~m} / \mathrm{s}$. Note that the spikes which do not vary with range are due to interference
Three periods of radar scattering are evidenced by these plots. In Fig. 4, a region of strong scattering appeared at 2223 UT in the gate at range $244 \mathrm{~km}$ and moved towards the radar with a negative range rate of about $90-110 \mathrm{~m} / \mathrm{s}$. This event looks like the so-called striations observed with the MU radar (Yamamoto et al., 1991, 1992, 1994; Woodman et al., 1991), except that one band only is observed. Before this event, scattering was observed between 2108 and 2143 UT (Fig. 3) and no scattering was detected in the period 2143 to 2220 UT. Figure 5 shows a colour plot for the mean Doppler velocity computed as the first moment of the Doppler spectra. This plot was obtained by considering the spectra only when SNR was larger than $5 \mathrm{~dB}$ and the raw data were interpolated in range and in time. This procedure was used to smooth the plot but, of course, it does not improve the resolutions in range and time, which are $22 \mathrm{~km}$ and $80 \mathrm{~s}$, respectively. In the timeperiod 2110-2115 UT the Doppler velocity varied from a maximum positive value near $25 \mathrm{~m} / \mathrm{s}$ (towards the radar) near 2112 UT to a minimum value near $-130 \mathrm{~m} / \mathrm{s}$ (away from the radar) in the interval 2114-2125 UT and the velocity again became weakly positive in the period between 2136 and 2145 UT. Within the third scattering region observed between 2223 and 2240 UT the velocity was positive at the southern border and negative on the northern border. Figure 5 shows variations in the Doppler velocity with quasi-periods between 10 and $30 \mathrm{~min}$.

\subsection{Ionosonde Es data}

Figure 6 presents four vertical ionograms recorded at Grenoble in the time-period 2058-2152 UT. At 2058 UT (Fig. 6a) the critical frequency of the Es-layer was $4 \mathrm{MHz}$. It increased rapidly to reach $9.5 \mathrm{MHz}$ at 2112 UT (Fig. 6b) and then decreased to smaller values near $4 \mathrm{MHz}$. At 2112 UT the Es-layer trace was rather irregular due to variations in the virtual height within two or three range bins during the frequency sweep (one range bin is $3 \mathrm{~km}$ wide). Significant spread of the Es



Fig. 4. Time evolution of E-region aspect sensitive echoes at $9 \mathrm{MHz}$ in azimuth $10^{\circ} \mathrm{W}$, in the time-period 2211-2314 UT. The Doppler spectrum at any cell is logarithmic on a $20-\mathrm{dB}$ scale with the Doppler velocity ranging from 140 to $140 \mathrm{~m} / \mathrm{s}$. A scattering region forming a band with a negative range rate of about 90 $110 \mathrm{~m} / \mathrm{s}$ is observed between 2223 and 2241 UT 


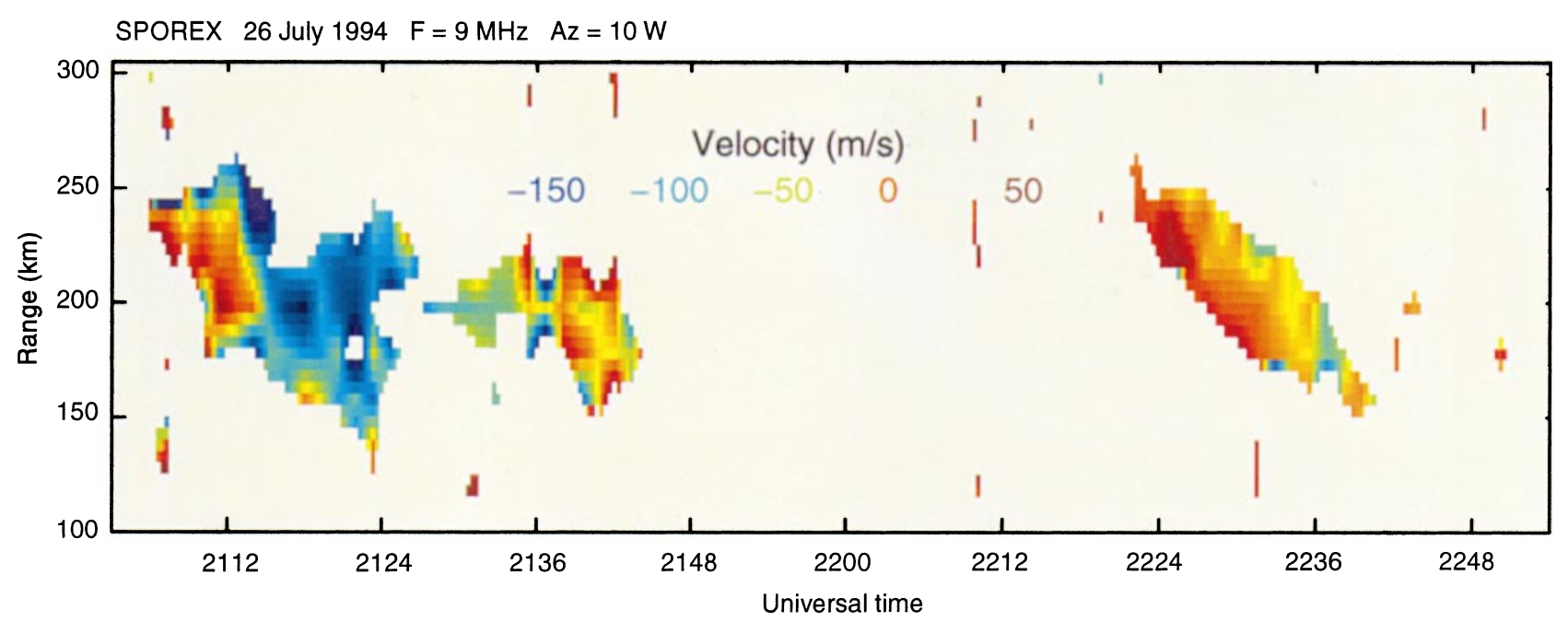

Fig. 5. Plot of the Doppler velocity during the E-region scattering event. Note the small positive velocities $(\sim 25 \mathrm{~m} / \mathrm{s})$ in the scattering regions with negative range rate and the large negative velocities $(-100$ to $-150 \mathrm{~m} / \mathrm{s})$ observed in the scattering regions with a positive range rate

trace was observed at 2125 UT (Fig. 6c) and it was accompanied by a spreading of the F-region echoes at greater heights. At 2152 UT the Es virtual height of the Es-layer was largely constant during the frequency sweep and the spread $\mathrm{F}$ began to disappear (Fig. 6d).

Figure 7 shows the time variations of three Es-layer parameters: (a) virtual height measured at four frequencies, (b) the critical frequency of the layer and (c) the Doppler velocity. It should be noted that the uncertainty on the virtual height values is about $\pm 3 \mathrm{~km}$ (height resolution), so most of the fluctuations observed in Fig. $7 \mathrm{a}$ are significant. Several peaks in the virtual height of reflection between 140 and $107 \mathrm{~km}$ are observed in Fig. 7a at the highest sounding frequency $(4.2 \mathrm{MHz})$. At the highest frequencies variations in the height are larger than at the lowest frequencies, which could suggest the possible existence of several plasma clouds within the antenna field of view. The maximum plasma frequency of the layer exhibited a large increase between 2105-2120 UT and a decrease after 2135 UT (Fig. 7b). The layer apparently moved up in the timeinterval 2140-2150 UT and then disappeared (except at the lowest frequency) (Fig. 7a). The layer appeared again near 2221 UT at a virtual height of $135 \mathrm{~km}$ and apparently moved down quickly. It is difficult to interpret the data of vertical soundings to infer the real altitude of the layer because the reflection points are not necessarily overhead. This is particularly true for sporadic-E layers which, at times, can be very irregular (Whitehead, 1972, 1989; From and Whitehead, 1986). In the event presented here, the time derivative of the virtual height is not in good agreement with the measured Doppler velocity. For instance, in the interval 2222-2230 UT, the virtual height variations give an average $\mathrm{d} h / \mathrm{d} t$ value between 40 and $60 \mathrm{~m} / \mathrm{s}$, which does not compare so well with the maximum $35 \mathrm{~m} / \mathrm{s}$ measured Doppler velocity (Fig. 7c). In the radar observations the apparent downward movement of the Es-layer is accompanied by a negative range rate of the scattering region of about $90-110 \mathrm{~m} / \mathrm{s}$ (Fig. 5).

\subsection{Ionosonde F-layer data}

F-layer data are shown in Fig. 8. Parts a and b show the F-region virtual heights and Doppler velocities, respectively. Long-period fluctuations of the virtual heights are observed, appearing first and with the strongest amplitude at high altitudes, corresponding to the largest frequencies. Hunsucker (1982) has presented a review on atmospheric gravity waves (AGWs) and their ionospheric manifestation as travelling ionospheric disturbances (TIDs) and Georges (1967) has presented several examples of TIDs, as observed with ionosondes, very similar to the data presented in Fig. 8a. In particular the fact that the perturbation was observed first at high virtual heights can be explained by the inclination of the wave front of the AGW (see e.g. Figs. 6.6 and 6.7 in Georges, 1967). The Doppler velocity also showed variations, from -25 to $25 \mathrm{~m} / \mathrm{s}$, and, except for few data points between 2112 and 2120 UT, the sign of the Doppler velocity was in agreement with the virtual height variations: positive (negative) Doppler velocity when the virtual height decreased (increased). Since the Doppler shift of the echoes is proportional to the time derivative of the integral of the phase path along the ray path, for F-region echoes we cannot easily link height variations to Doppler velocities. It should be noted in Fig. $8 \mathrm{~b}$ that short periodicities (10-20 min) were superposed on the long-period (60-70 min) fluctuations, as was observed in the Doppler velocity of radar data (Fig. 5).

\section{Experimental data 28 July 1994}

\subsection{Radar data}

The second event occurred on 28 July 1994. Figures 9 and 10 present data at $9 \mathrm{MHz}$ in the same format as in Figs. 3 and 4. At the beginning of the event (2315-2348 
a

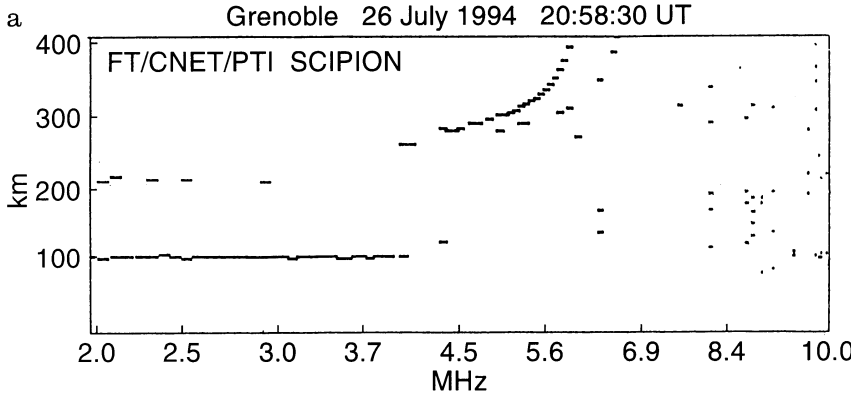

$\mathrm{b}$
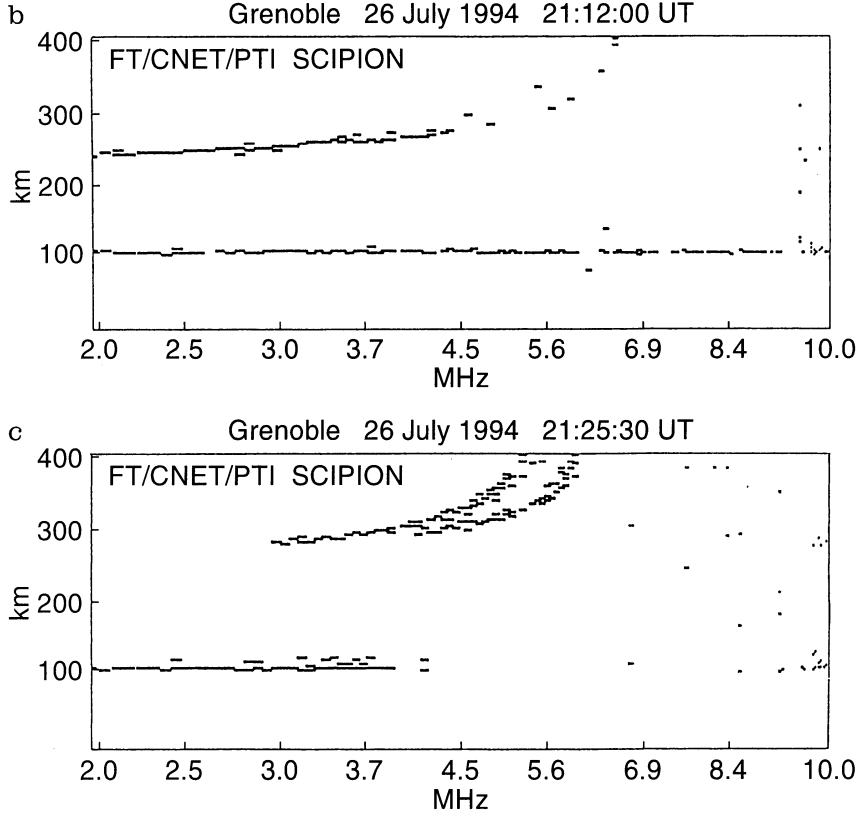

d

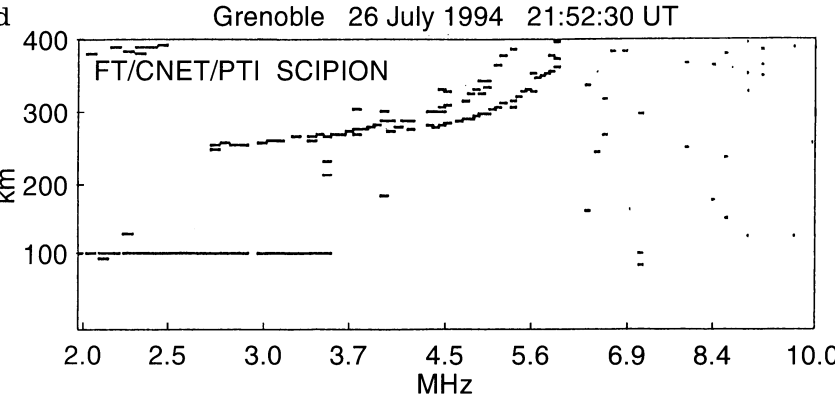

Fig. 6a-d. Four vertical ionograms at different time: a 2058 UT scattering is not yet observed at the radar. b 2112 UT - strong scattering is observed at the radar; the critical frequency of the Es trace is high $(>9 \mathrm{MHz})$ and the Es trace is irregular because of the variations of the virtual height of reflection with frequency.c 2125 UT - scattering is still strong at the radar; the critical frequency of the Es layer has decreased and the Es trace shows a complex structure which could be due to oblique reflections or to reflections on multiple layers. Spread F is observed at higher heights. d 2152 UT - scattering has disappeared at the radar; the Es trace is now smooth because the virtual height does not vary with frequency and the spread $\mathrm{F}$ begins to disappear

UT), the range of the scattering region increased, resulting in an apparent average northward velocity between 70 and $90 \mathrm{~m} / \mathrm{s}$ (Fig. 9). The next time-period 2350-0053 UT (Fig. 10) exhibited pseudo-oscillatory behaviour in the range of the scattering region with a pseudo-period near 50-60 min. This second event shows a backscattering region receding and approaching the radar, which is different from the striations with constant slopes observed by the MU radar (see e.g. Fig. 1 in Woodman et al., 1991).

\subsection{Ionosonde observations}

Parts $\mathrm{a}, \mathrm{b}$ and $\mathrm{c}$ of Fig. 11 show the variations in the F-region virtual height, the F-region Doppler velocity and the Es-layer virtual height, respectively. Not shown here are the critical frequency of the Es-layer, which varied between 3 and $6 \mathrm{MHz}$ during the time-period considered, and the Doppler velocity of Es echoes, which was very small $(<5 \mathrm{~m} / \mathrm{s})$.

The virtual height variations of $F$ echoes show a clear signature of the passage of an AGW (Fig. 11a) and this is confirmed by the variations in the Doppler velocity (Fig. 11b). By comparing the radar data (Figs. 9 and 10) with the ionosonde data (Fig. 11) we observe that radarrange variations seem to be correlated with the virtual height variations of Es echoes in Fig. 11c. When the virtual height of Es echo increases the radar-range rate is positive and the opposite is true. For instance during the time-interval indicated by the letter A in Figs. 9 and 11 (2320-2345 UT) the virtual height increases and the scattering region recedes from the radar; in the interval indicated by B in Figs. 10 and 11 (0002-0050 UT) the virtual height increases, then decreases and then increases again, and the scattering region was observed to recede, then to approach the radar and then to recede again.

\section{Discussion and concluding remarks}

We have presented mid-latitude observations of sporadic-E irregularities from the Valensole HF radar, in conjunction with ionosonde measurements made on July 1994.

In these observations we found quasi-periodic echoes in the radar data with a quasi-period between 10 and $70 \mathrm{~min}$. In a previous study we had found shorter periods from 10 to $30 \mathrm{~min}$ (Bourdillon et al., 1995). Though we are not absolutely sure that the measured virtual height variations in the ionosonde data were true variations of the height of the layer because angle measurements were not available, the comparison between the radar data and the ionosonde measurements suggests that the variations of the range of the echoing region are associated with variations in the height of the Es-layer. This effect was particularly clear for the event observed on 28 July, showing a scattering region moving alternately away and towards the radar while the Es-layer was apparently moving up and down. Woodman et al. (1991) have introduced the idea of an Es-layer modulated in altitude by the passage of a gravity wave to explain the radar striations in the $\mathrm{MU}$ radar observations performed in Japan at $46.5 \mathrm{MHz}$. In their model, a resonance mechanism between the AGWs 

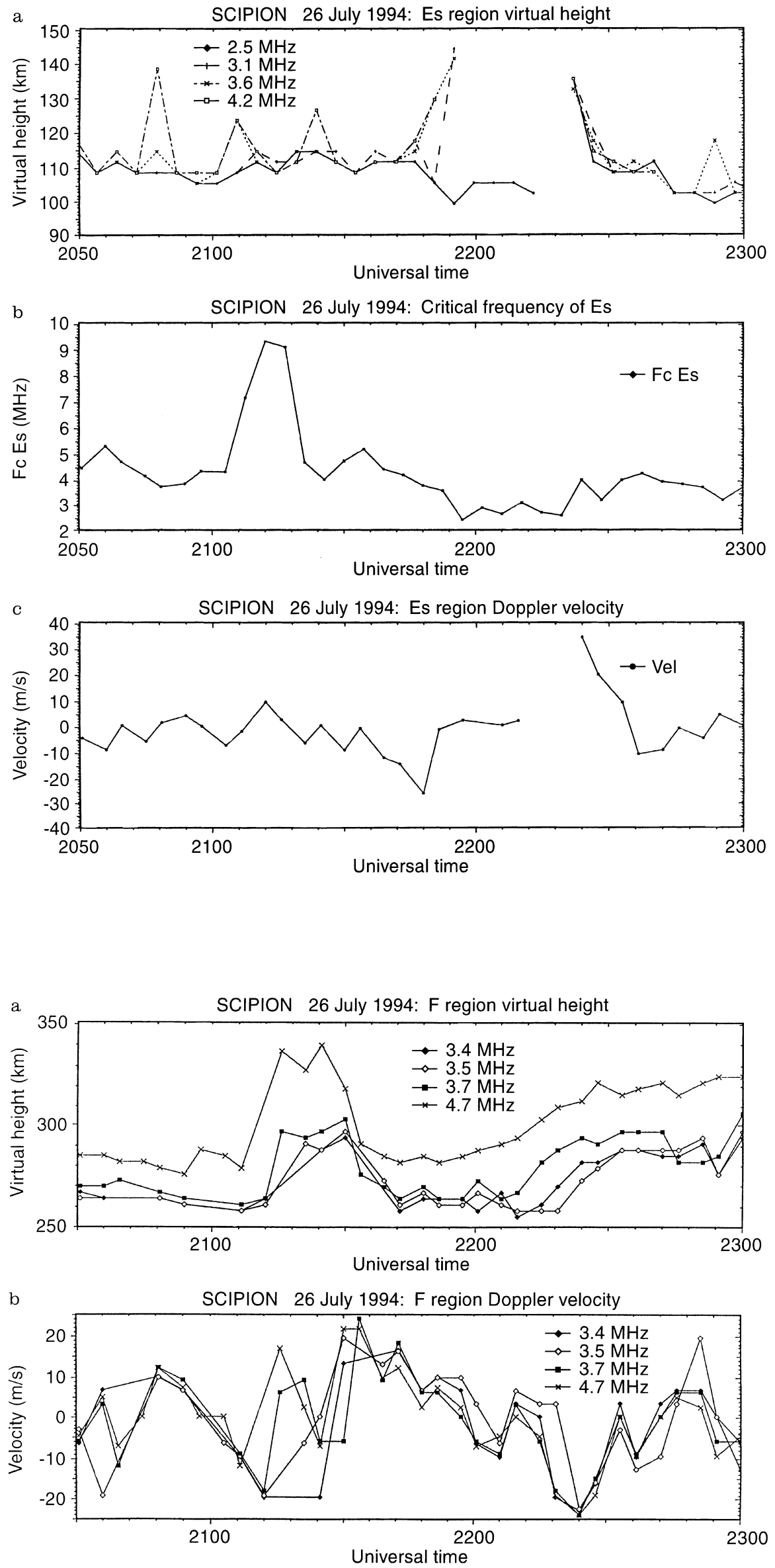

Fig. 7a-c. Data from vertical sounding measurements on sporadic-E echoes: a virtual height, $\mathbf{b}$ critical frequency and $\mathbf{c}$ Doppler velocity all versus time
Fig. 8a, b. Data from vertical sounding measurements of F-region echoes: a virtual height and b Doppler velocity both versus time 


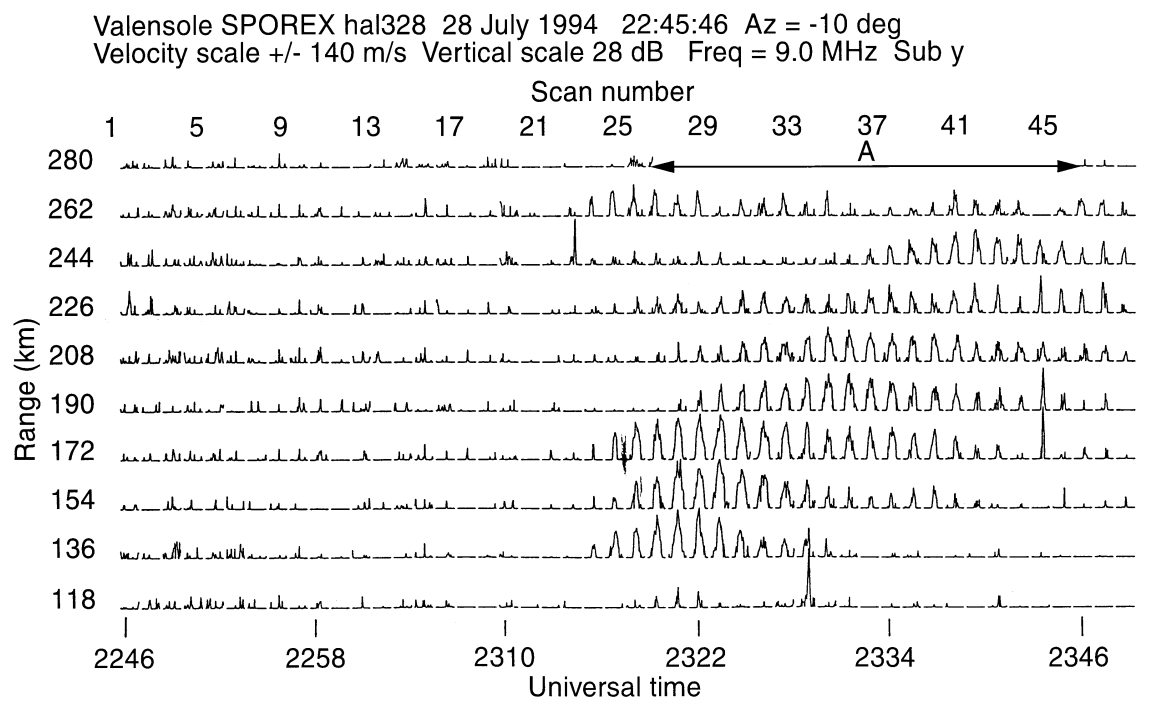

Fig. 9. Time evolution of E-region magnetic aspect sensitive echoes at $9 \mathrm{MHz}$ in azimuth $10^{\circ} \mathrm{W}$ in the time-period 2245-2348 UT. The Doppler spectrum at any cell is logarithmic on a $28-\mathrm{dB}$ scale with the Doppler velocity ranging from -140 to $140 \mathrm{~m} / \mathrm{s}$. A region of backscattering, forming a band with a positive range rate of about $70-90 \mathrm{~m} / \mathrm{s}$, is observed from 2317 UT to the end of the record at 2348 UT and the plasma is necessary to obtain a significant height modulation, and such a resonance should be obtained for short-period (5-10 min) AGWs only. The data presented here support the idea proposed by Woodman et al. (1991) of gravity wave modulation of Es-layers, but the large periods observed cannot support a resonance mechanism. In a recent numerical study Huang and Kelley (1996) have shown that spatial resonance is not required to obtain significant modulation of the height of an Es-layer, but their work should be extended to longer-period waves to account for our observations.

In Fig. 5, inside the bands formed by range variations of the region of backscattering, the plot shows a tendency for positive velocities when the backscattering region approaches the radar and negative velocities when it is receding. From these data and others not shown here, the positive velocities are usually small $(\sim 25-50 \mathrm{~m} / \mathrm{s})$, but the negative velocities can reach high values $(-100$ to $-150 \mathrm{~m} / \mathrm{s})$. These characteristics show that scattering by sporadic-E irregularities observed at
HF has similarities with scattering observed by the MU radar at VHF (Yamamoto et al. 1991, 1992, 1994; Tsunoda et al. 1994); the main difference is in the quasiperiods of the large-scale fluctuations which are observed to be longer at Valensole (10-70 min) than at the MU radar (5-10 min).

We have noted the appearance of spread $F$ on the ionograms during the passage of the gravity wave. It is known that the main source of spread-F echoes is the modulation of the $\mathrm{F}$ layer by medium-scale gravity waves (Fejer and Kelley, 1980; Bowman, 1990). The initiation of mid-latitude F-region instability by gravity waves was studied theoretically by Huang et al. (1994), who extended the instability mechanism first proposed by Perkins (1973). Some correlation between spread-F and Es scattering seems to be observed in our data. To establish such a correlation one should account for the time-delay between the passage of the perturbation in the F- and in the Es-layer, which is not so easy because the knowledge of the characteristics of propagation of the gravity waves is required.

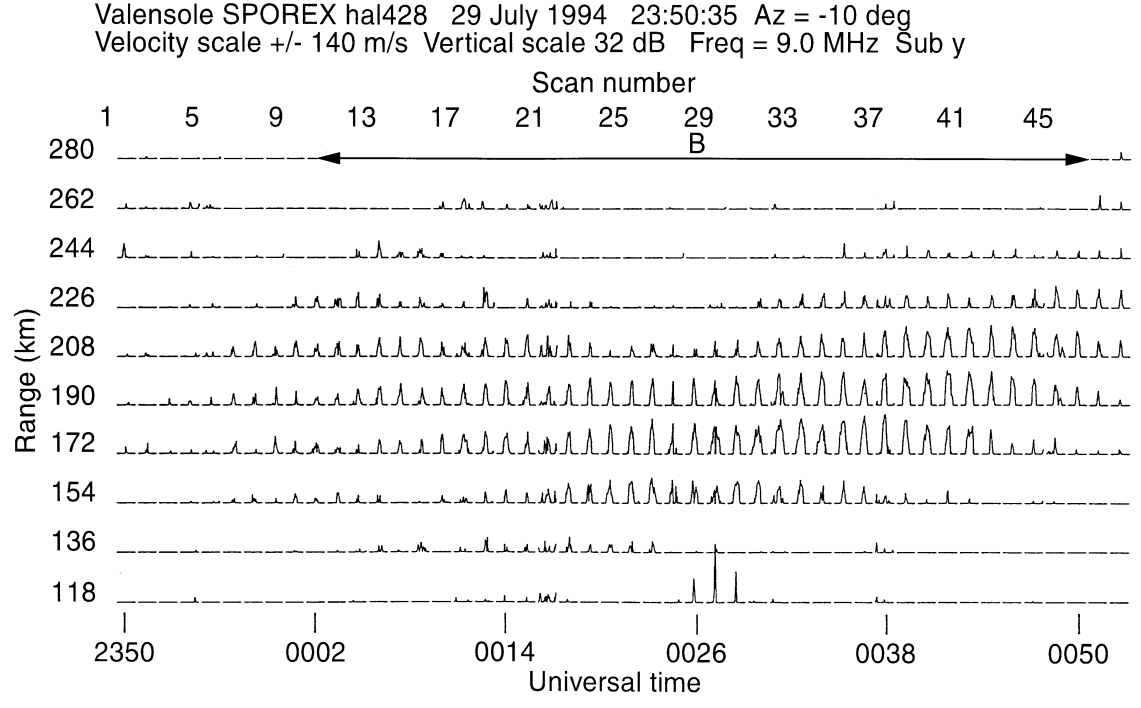

Fig. 10. Time evolution of E-region magnetic aspect sensitive echoes at $9 \mathrm{MHz}$ in azimuth $10^{\circ} \mathrm{W}$, in the time-period $2350-0053$ UT. The Doppler spectrum at any cell is logarithmic on a 32-dB scale with the Doppler velocity ranging from -140 to $140 \mathrm{~m} / \mathrm{s}$. The range of the scattering region varies with time and seems to show a quasi-oscillatory behaviour 

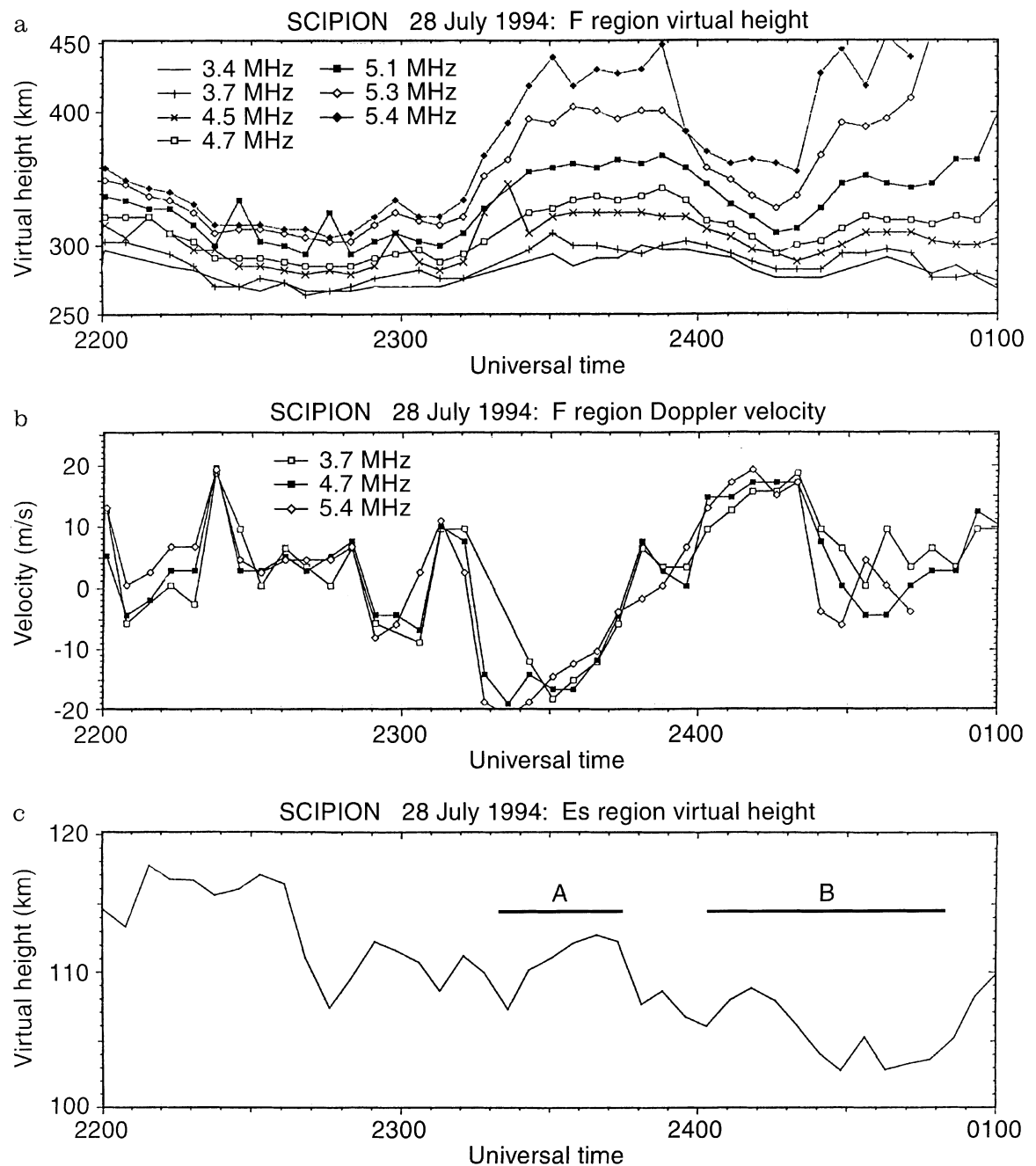

Fig. 11a-c. Data from vertical sounding measurements of F-region echoes: a virtual heights and b Doppler velocity. The third plot $\mathbf{c}$ shows the virtual height of the Eslayer at the smallest sounding frequency $(2.5$ $\mathrm{MHz}$ ). The time-intervals $\mathrm{A}$ and $\mathrm{B}$ refer to those indicated in Figs. 9 and 10, respectively
Acknowledgements. Operation of the Valensole radar is supported by the University of Paris VI. The authors are grateful for the assistance of Michel Six and the Valensole CNRS technician Jacques Legros. Partial support for the completion of this work was provided by the French-Greek collaborative program PLATON, project number $184340 \mathrm{~L}$. The authors thank the referees for helpful comments.

Topical Editor D. Alcaydé thanks K. Schlegel and another referee for their help in evaluating this paper.

\section{References}

Bourdillon, A., C. Haldoupis, and J. Delloue, High-frequency Doppler radar observations of magnetic aspect sensitive irregularities in the mid-latitude E-region ionosphere, J. Geophys. Res., 100, 21503-21521, 1995.

Bowman, G. G., A review of some recent work on mid-latitude spread $\mathrm{F}$ occurrence as detected by ionosonde, J. Geomagn. Geoelectr., 42, 109-138, 1990.

Ecklund, W. L., D. A. Carter, and B. B. Balsley, Gradient drift irregularities in mid-latitude sporadic E, J. Geophys. Res., 86, 858-862, 1981.

Fejer, B. G., and M. C. Kelley, Ionospheric irregularities, Rev. Geophys., 18, 401-454, 1980.

From, W. R., and J. D. Whitehead, Es structure using an HF radar, Radio Sci., 21, 309-312, 1986.
Fukao, S., M. C. Kelley, T. Shirakawa, T. Takami, M. Yamamoto, T. Tsuda, and S. Kato, Turbulent upwelling of the mid-latitude ionosphere. 1, Observational results by the MU radar, $J$. Geophys. Res., 96, 3725-3746, 1991.

Georges, T. M., Ionospheric effects of atmospheric waves, ESSA Tech. Rep., IER-57/ITSA-54, ESSA, Washington DC, 1967.

Goodwin, G. L., Some aspects of direct backscatter echoes from sporadic-E, J. Atmos. Terr. Phys., 27, 777-793, 1965.

Haldoupis, C., and K. Schlegel, A 50-MHz radio Doppler experiment for mid-latitude E-region coherent backscatter studies: system description and first results, Radio Sci., 20, 959-978, 1993.

Huang, C. S., and M. C. Kelley, Numerical simulations of gravity wave modulation of mid-latitude sporadic-E-layers, J. Geophys. Res., 101, 24533-24543, 1996.

Huang, C. S., C. A. Miller, and M. C. Kelley, Basic properties and gravity wave initiation of the mid-latitude F-region instability, Radio. Sci., 29, 395-405, 1994.

Hunsucker, R. D., Atmospheric gravity waves generated in the high-latitude ionosphere: a review, Rev. Geophys. Space. Phys., 20, 293-315, 1982.

Keys, J. G., and M. K. Andrews, Gravity wave and sporadic-E echo signatures on VHF backscatter radar systems, Planet. Space Sci., 32, 1455-1462, 1984.

Perkins, F., Spread F and ionospheric currents, J. Geophys. Res., 78, 218-226, 1973.

Riggin, D., W. E. Swartz, J. Providakes, and D. T. Farley, Radar studies of long-wavelength waves associated with sporadic-E layers, J. Geophys. Res., 91, 8011-8024, 1986. 
Six, M., J. Parent, A. Bourdillon, and J. Delloue, A new multibeam receiving equipment for the Valensole skywave $\mathrm{HF}$ radar: description and applications, IEEE Trans. Geosci. Remote Sens., 34, 708-719, 1996.

Sudan, R. N., J. Akinrimisi, and D. T. Farley, Generation of smallscale irregularities in the equatorial electrojet, J. Geophys. Res., 78, 240-248, 1973.

Tanaka, T., and S. V., Venkateswaran, Characteristics of fieldaligned E-region irregularities over Iioka $(36 \mathrm{~N})$, Japan, I, $J$. Atmos. Terr. Phys., 44, 381-393, 1982a.

Tanaka, T., and S. V., Venkateswaran, Characteristics of fieldaligned E-region irregularities over Iioka (36 N), Japan, II, J. Atmos. Terr. Phys., 44, 395-406, 1982 b.

Tsunoda, R. T., S. Fukao, and M. Yamamoto, On the origin of quasi-periodic radar backscatter from mid-latitude sporadic-E, Radio Sci., 29, 349-365, 1994.

Whitehead, J. D., The structure of sporadic-E from a radio experiment, Radio Sci., 7, 355-358, 1972.
Whitehead, J. D., Recent work on mid-latitude and equatorial sporadic-E, J. Atmos. Terr. Phys., 51, 401-424, 1989.

Woodman, R. F., M. Yamamoto, and S. Fukao, Gravity wave modulation of gradient drift instabilities in mid-latitude sporadic-E, Geophys. Res. Lett., 18, 1197-1200, 1991.

Yamamoto, M., S. Fukao, R. F. Woodman, T. Ogawa, T. Tsuda, and S. Kato, Mid-latitude E-region field-aligned irregularities observed with the MU radar, J. Geophys. Res., 96, 1594315949, 1991.

Yamamoto, M., S. Fukao, T. Ogawa, T. Tsuda, and S. Kato, A morphological study on the mid-latitude E-region field-aligned irregularities observed with the MU radar, J. Atmos. Terr. Phys., 54, 769-777, 1992.

Yamamoto, M., N. Komoda, S. Fukao, R. T. Tsunoda, T. Ogawa, and T. Tsuda, Spatial structure of the E-region field-aligned irregularities revealed by the MU radar, Radio Sci., 29, 337-347, 1994. 